\title{
Studi Evolusi Struktur pada Deposisi Tembaga Dalam Substrat Silikon Dengan Metode Dinamika Molekuler
}

\author{
Study of Structure Evolution of Copper Deposition on Silicon Substrate \\ using Molecular Dynamics Method
}

\author{
Aulia Fikri Hidayat \\ Program Studi Farmasi, FMIPA, Universitas Islam Bandung \\ aulia.fikri.h@unisba.ac.id
}

\begin{abstract}
Abstrak. Metode dinamika molekuler digunakan untuk mempelajari deposisi atom tembaga $(\mathrm{Cu})$ pada substrat silikon $(\mathrm{Si})$. Interaksi atom-atom $\mathrm{Si}-\mathrm{Si}, \mathrm{Cu}-\mathrm{Cu}$, dan $\mathrm{Cu}-\mathrm{Si}$ masing-masing dideskripsikan dengan potensial interatomik Tersoff, MEAM, dan Morse. Ensembel NVE dan termostat Berendsen digunakan dalam simulasi ini. Kemudian diinvestigasi pengaruh parameter kecepatan awal dan laju deposisi terhadap persentase struktur amorf, fungsi distribusi radial (RDF), dan bilangan koordinasi. Hasil simulasi menunjukkan perbedaan yang signifikan terhadap persentase struktur amorf pada parameter yang bervariasi. Investigasi pasca-simulasi menunjukkan variasi pada nilai RDF dan bilangan koordinasi.
\end{abstract}

Kata kunci: Metode dinamika molekuler, evolusi struktur, fungsi distribusi radial, bilangan koordinasi

\begin{abstract}
The Molecular dynamics method was used to study the deposition of copper $(\mathrm{Cu})$ atoms onto silicon ( $\mathrm{Si}$ ) substrate. The interaction of $\mathrm{Si}-\mathrm{Si} \mathrm{Cu}-\mathrm{Cu}$, and $\mathrm{Cu}-\mathrm{Si}$ atoms were described by Tersoff, MEAM, and Morse interatomic potentials respectively. NVE ensemble and Berendsen thermostat was used in this simulation. The effect of initial velocity and deposition rate on the percentage of amorphous structure, radial distribution function (RDF), and coordination number was investigated. The result showed significant differences of amorphous structure percentage at varied parameters. Post-simulation investigation showed variation in RDF and coordination number.
\end{abstract}

Keywords: Molecular dynamics method, structure evolution, radial distribution function, coordination number

\section{Pendahuluan}

Algoritma matematika merupakan kaidah fundamental untuk mendeskripsikan proses dari sebuah permasalahan atau fenomena, dimana dewasa ini penerapannya semakin variatif dan kompleks. Dalam bidang teknologi keamanan data, algoritma Data Encryption Standard (DES) merupakan salah satu algoritma yang umum digunakan untuk menjamin validitas informasi [1]. Algoritma matematika juga merupakan dasar dalam pemodelan atau simulasi dinamika molekuler yang memiliki ranah kajian cukup luas khususnya dalam penelitian bidang sains dan teknologi material, kimia fisika, serta biomolekuler. Metode dinamika molekuler memanfaatkan algoritma matematika untuk mengkaji sistem kompleks dalam skala atomik dan molekul. Secara umum, dinamika molekular diaplikasikan pada sistem dengan jumlah atom terbatas dan cenderung sulit dibandingkan dengan sistem makroskopik secara langsung. Karena itu, sistem yang dimodelkan perlu dikonstruksi seefektif mungkin dengan mempertimbangkan batas-batas periodik agar sedemikian rupa merepresentasikan sistem makroskopik (bulk).

Secara mendasar, metode dinamika molekuler bekerja berdasarkan persamaan gerak klasik Newton dan dilakukan analisis evolusi yang terjadi terhadap partikel (atom atau molekul) dari waktu ke waktu sehingga diperoleh solusi numerik pada batasan tertentu. Beberapa hal perlu 
dipertimbangkan ketika menggunakan simulasi dinamika molekuler. Diantaranya yaitu fungsi potensial untuk memodelkan interaksi partikel pada sistem yang akan diinvestigasi, algoritma integrasi waktu (time integration algorithm), syarat batas periodik, rentang waktu (timestep), penggunaan termostat, serta parameter-parameter statistik yang akan digunakan selama proses simulasi [2].

Salah satu algoritma persamaan gerak spesifik yang digunakan dalam metode dinamika molekuler yaitu algoritma Verlet [3] yang mendeskripsikan posisi partikel dengan selang waktu $\delta t$ yang diberikan oleh persamaan

$$
r(t+\delta t)=2 r(t)-r(t-\delta t)+a(t) \delta t^{2}
$$

Dinamika molekuler memungkinkan aspek kajian antardisiplin ilmu, khususnya yang berkaitan dengan fenomena di level molekuler. Dalam kajian teknologi material metode ini telah digunakan untuk mendeskripsikan fenomena deposisi atom alumunium ke atas permukaan tembaga [4], transisi fasa nanoklaster nikel [5], serta mekanisme sintesis grafena di atas nikel [6]. Dalam kajian di bidang farmasi, dinamika molekuler dimanfaatkan sebagai perangkat komputasi dalam penemuan obat (drug discovery) [7]. Pada penelitian ini metode dinamika molekuler dimanfaatkan untuk mengkaji evolusi yang terjadi pada atom-atom logam tembaga $(\mathrm{Cu})$ selama dideposisikan ke atas substrat silikon ( $\mathrm{Si}$ ) hingga tercapai struktur akhir. Kemudian dilakukan analisis untuk diperoleh informasi mengenai fungsi distribusi radial dan bilangan koordinasi pada beberapa variasi paramater.

\section{Simulasi Dinamika Molekuler}

Secara keseluruhan, proses dinamika molekuler dalam penelitian ini melibatkan tiga tahap yaitu tahap pra-pemrosesan (pre-processing), proses simulasi utama, serta tahap pasca-pemrosesan (postprocessing). Dua tahap pertama dilakukan dengan menggunakan perangkat lunak LAMMPS (Largescale Atomic/Molecular Massively Parallel Simulator), sebuah perangkat lunak open source yang dikembangkan oleh Sandia National Laboratories. Tahap terakhir dilakukan dengan bantuan perangkat lunak Ovito (The Open Visualization Tool). Pada tahap pra-pemrosesan dilakukan konstruksi dimensi simulasi pada sumbu- $x y z \quad 4 a \times 4 a \times 8 a$, dengan dimensi substrat silikon $4 a \times 4 a \times 3 a$. Sumbu- $x$ dan $y$ diatur periodik, sedangkan sumbu- $z$ diatur tetap. Nilai $a$ mendeskripsikan nilai konstanta kisi silikon yaitu 5,43 $\AA$ [8]. Dengan nilai tersebut diperoleh dimensi substrat silikon sebesar $(21,72 \times 21,72 \times 16,29) \AA$, yang tersusun atas 416 atom silikon.
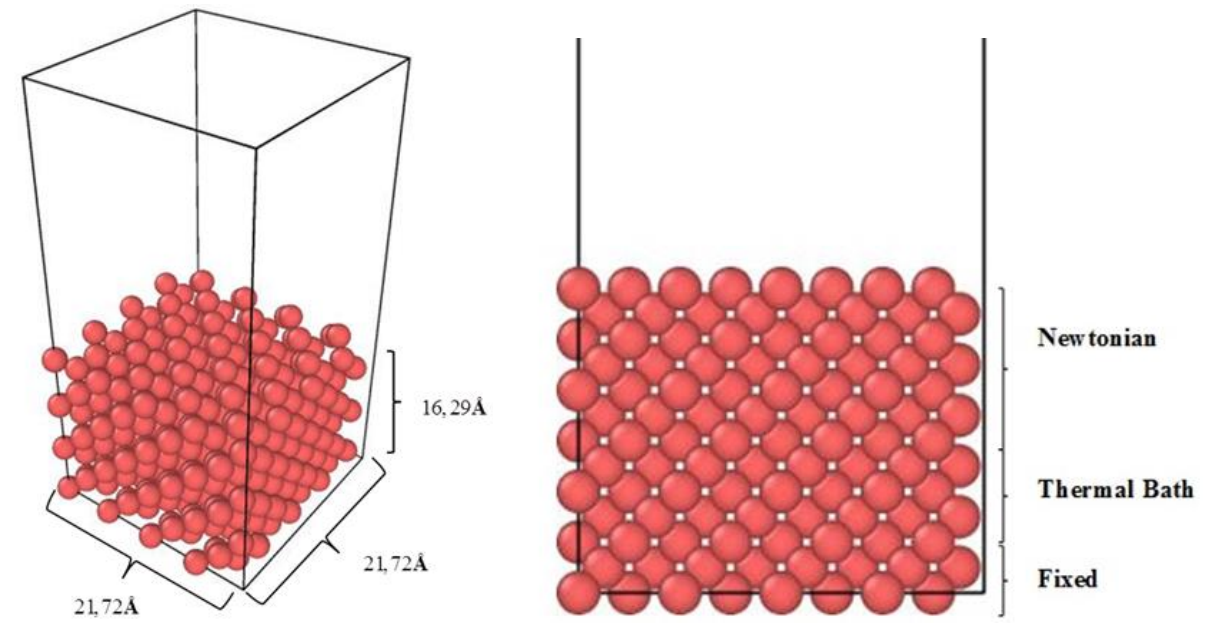

Gambar 1. Dimensi dan pembagian tiga area substrat selama simulasi deposisi 
Substrat dibagi menjadi tiga area selama proses simulasi berlangsung. Area terbawah diatur tetap untuk mencegah bergeraknya substrat selama proses deposisi. Dua area di atasnya merupakan lapisan yang dikontrol oleh temperatur, dimana area kedua merupakan area thermal bath dan area paling atas merupakan area transfer. Pergerakan atom di dua area ini ditentukan oleh persamaan gerak Newton.

Pada simulasi dalam penelitian ini digunakan ensembel mikrokanonik untuk pembaharuan (update) posisi dan kecepatan pada tiap timestep $(\Delta t)$. Pada ensembel mikrokanonik besaranbesaran jumlah partikel $(N)$, volume sistem $(V)$, dan total energi $(E)$ diatur konstan selama proses simulasi berlangsung. Termostat Berendsen diaplikasikan untuk menjaga temperatur konstan. Sebagai langkah awal dilakukan ekuilibrasi simulasi dengan timestep 1 fs selama 50 ps pada temperatur $500 \mathrm{~K}$. Ekuilibrasi diperlukan untuk memberikan gambaran timestep yang dipakai selama simulasi utama. Setelah ekuilibrasi selesai, dilakukan fase utama simulasi yaitu proses deposisi atom tembaga ke atas substrat silikon. Proses simulasi deposisi dilakukan dengan timestep 0,2 fs selama 100 ps.

Untuk mendeskripsikan interaksi antaratom atau antarmolekul, digunakan beberapa fungsi potensial interaksi. Fungsi potensial interaksi antara ikatan $\mathrm{Cu}-\mathrm{Cu}$, ikatan $\mathrm{Cu}-\mathrm{Si}$, dan ikatan $\mathrm{Si}-\mathrm{Si}$ masing-masing dideskripsikan oleh potensial MEAM (modified-embedded atom method) [9], potensial Morse [10], dan potensial Tersoff [11] dengan masing-masing parameter ditunjukkan pada tabel 1-3.

Tabel 1. Parameter MEAM ikatan $\mathrm{Cu}-\mathrm{Cu}$

\begin{tabular}{|l|l|}
\hline$E_{\mathrm{c}}(\mathrm{eV})$ & 3.54 \\
\hline$a_{0}(\AA)$ & 3.62 \\
\hline$A$ & 1.07 \\
\hline$\alpha$ & 5.11 \\
\hline$\beta^{(0)}$ & 3.634 \\
\hline$\beta^{(1)}$ & 2.2 \\
\hline$\beta^{(2)}$ & 6.0 \\
\hline$\beta^{(3)}$ & 2.2 \\
\hline$t^{(0)}$ & 1.0 \\
\hline$t^{(1)}$ & 4.91 \\
\hline$t^{(2)}$ & 2.49 \\
\hline$t^{(3)}$ & 2.95 \\
\hline$C_{\min }$ & 0.8 \\
\hline$C_{\max }$ & 2.8 \\
\hline$\rho_{0}$ & 1.1 \\
\hline
\end{tabular}

Tabel 2. Parameter Morse ikatan $\mathrm{Cu}-\mathrm{Si}$

\begin{tabular}{|l|l|}
\hline$D(\mathrm{eV})$ & 0.900 \\
\hline$\alpha\left(\AA^{-1}\right)$ & 1.110 \\
\hline$r_{0}(\AA)$ & 3.150 \\
\hline
\end{tabular}


Tabel 3. Parameter Tersoff ikatan Si-Si

\begin{tabular}{|c|l|}
\hline$A(\mathrm{eV})$ & $1.8308 \times 10^{3}$ \\
\hline$B(\mathrm{eV})$ & $4.7118 \times 10^{2}$ \\
\hline$\lambda\left(\AA^{-1}\right)$ & 2.4799 \\
\hline$\mu\left(\AA^{-1}\right)$ & 1.7322 \\
\hline$\beta$ & $1.1000 \times 10^{-6}$ \\
\hline$n$ & $7.8734 \times 10^{-1}$ \\
\hline$c$ & $1.0039 \times 10^{5}$ \\
\hline$d$ & $4.384 \times 10^{0}$ \\
\hline$h$ & $-5.7058 \times 10^{-1}$ \\
\hline$R(\AA)$ & 1.8 \\
\hline$S(\AA)$ & 2.1 \\
\hline
\end{tabular}

Tahap pasca-pemrosesan dilakukan setelah selesainya proses simulasi utama. Analisis terhadap data trayektori dilakukan untuk memperoleh informasi evolusi struktur, fungsi distribusi radial, serta bilangan koordinasi. Fungsi distribusi radial (RDF) adalah fungsi korelasi pasangan yang memberikan gambaran mengenai probabilitas untuk menemukan atom-atom tetangga dari sebuah atom referensi pada radius tertentu. Secara matematis nilai RDF, $g(r)$, diberikan oleh persamaan

$$
g(r)=\frac{d}{d r}\left[\frac{n(r)}{\rho 4 \pi r^{2}}\right]
$$

dimana $n(r)$ adalah jumlah partikel pada radius $r$ dan $\rho$ adalah kerapatan jumlah partikel.

\section{Hasil dan Pembahasan}

\subsection{Evolusi Struktur dan Persentase Struktur Amorf}

Morfologi struktur akhir yang terbentuk setelah simulasi dan evolusi struktur amorf pada variasi kecepatan awal ditunjukkan pada gambar 2. Pada waktu 5 ps hingga 30 ps, simulasi dengan kecepatan awal $10 \AA /$ ps menghasilkan struktur amorf yang cenderung lebih tinggi dibandingkan dengan nilai kecepatan awal lainnya. Hal ini disebabkan dengan kecepatan yang cukup tinggi atom $\mathrm{Cu}$ merusak keteraturan Si untuk beberapa saat. Kemudian persentase struktur amorf-nya menurun pada 35 ps dan mengalami peningkatan dengan kestabilan yang sama dengan nilai kecepatan lainnya, hingga persentasenya mencapai 57,8\% pada akhir deposisi.

Fenomena yang menarik terlihat ketika membandingkan simulasi $2 \AA /$ ps dengan simulasi 4,286 $\AA /$ ps. Struktur amorf yang terbentuk pada simulasi $2 \AA /$ ps cenderung selalu lebih tinggi dibandingkan dengan simulasi 4,286 $\AA$ /ps. Hal ini berkaitan dengan posisi awal serta posisi akhir atom $\mathrm{Cu}$ yang didefinisikan secara acak oleh LAMMPS. Hal ini berimplikasi probabilitas suatu atom membentuk suatu struktur dengan atom lainnya juga akan cenderung acak sehingga mengakibatkan simulasi $2 \AA / p s$ memiliki probabilitas berikatan secara teratur dan membentuk struktur kristal yang lebih rendah dibandingkan simulasi 4,286 $\AA$ /ps. Dengan kata lain, simulasi $2 \AA /$ ps memiliki probabilitas membentuk struktur amorf yang lebih tinggi, dengan persentase mencapai $59,6 \%$ pada akhir deposisi.

Pada variasi laju deposisi, morfologi struktur akhir setelah simulasi dan evolusi struktur amorf ditunjukkan pada gambar 3. Perbedaan laju deposisi menghasilkan perbedaan persentase struktur amorf yang signifikan. Pada durasi deposisi yang sama, atom yang dideposisikan dengan laju deposisi tinggi akan lebih banyak dibandingkan laju deposisi rendah. Hal ini menyebabkan lebih 
banyak atom $\mathrm{Cu}$ yang merusak struktur kristal Si. Penggunaan laju deposisi tinggi meningkatkan persentase struktur amorf hingga mencapai $100 \%$ pada akhir deposisi (gbr. 3b). Hal ini mempengaruhi tidak adanya struktur kristal yang muncul pada akhir simulasi.

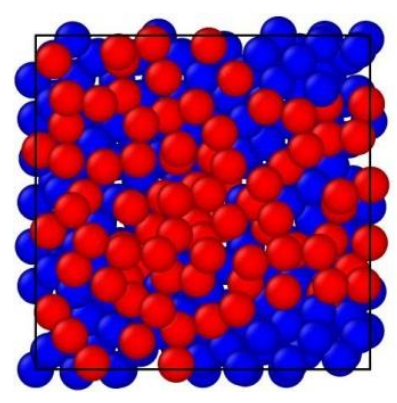

(a)

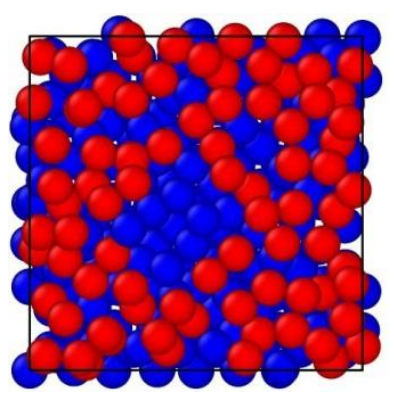

(b)

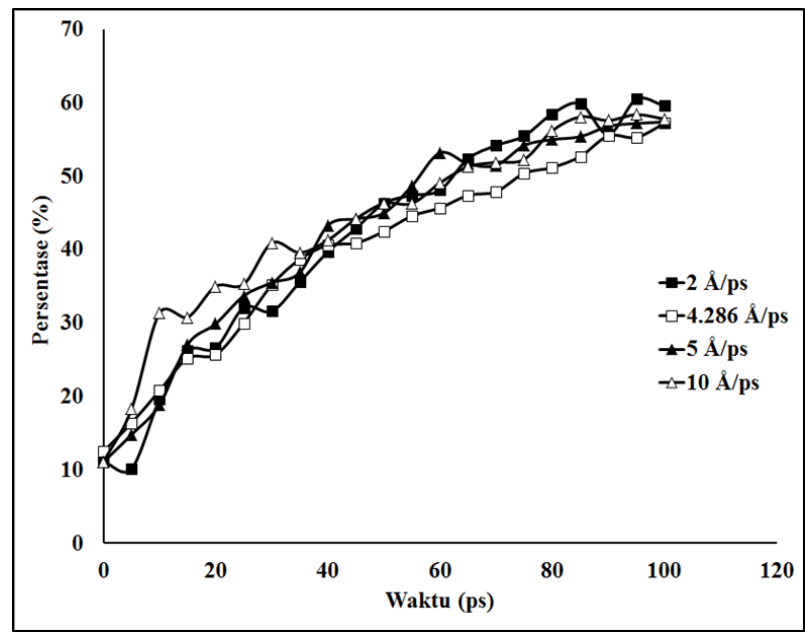

(c)

Gambar 2. Visualisasi tampak atas struktur pada akhir simulasi dengan kecepatan awal (a) $2 \AA / \mathrm{ps}$ dan (b) $10 \AA /$ ps (merah = amorf, biru = non-amorf), serta (c) kurva evolusi struktur amorf

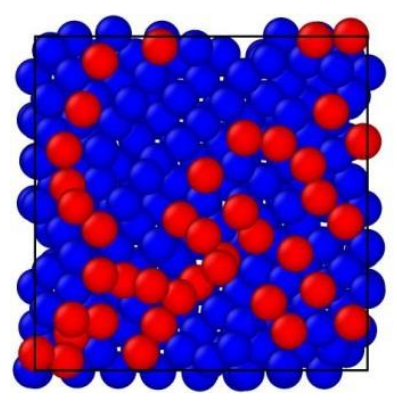

(a)

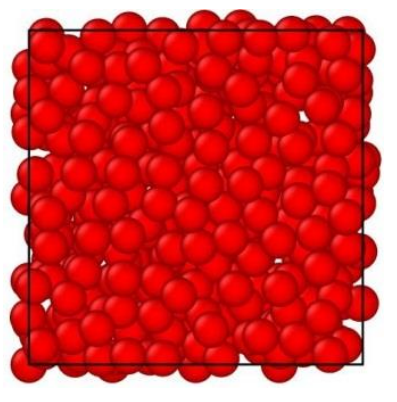

(b) 


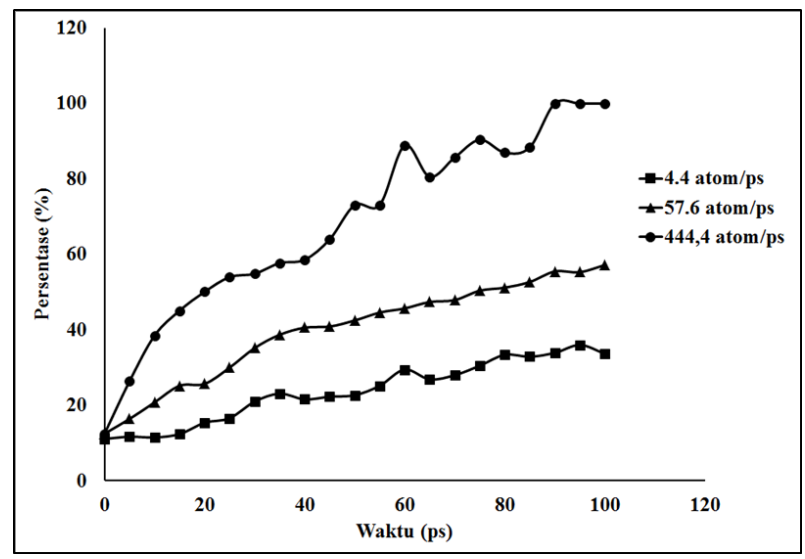

(c)

Gambar 3. Visualisasi tampak atas struktur pada akhir simulasi pada laju deposisi (a) 4,44 atom/ps dan (b) 444,4 atom/ps (merah = amorf, biru = non-amorf), serta (c) kurva evolusi struktur amorf

\subsection{Fungsi Distribusi Radial dan Bilangan Koordinasi}

Analisis fungsi distribusi radial (RDF) dan bilangan koordinasi dilakukan terhadap data setelah selesainya proses deposisi, yaitu ketika struktur terakhir telah selesai terbentuk. Ini dilakukan untuk menginvestigasi pengaruh masing-masing variasi parameter terhadap kerapatan atom atau probabilitas menemukan atom-atom tetangga dari sebuah atom referensi pada radius tertentu pada struktur akhir setelah simulasi. Puncak pertama RDF dari sistem $\mathrm{Cu}-\mathrm{Si}$, baik pada variasi kecepatan awal (gbr. 4a) maupun variasi laju deposisi (gbr. 5a) berada pada kisaran radius 3,05-3,15 $\AA$. Nilai ini konsisten dengan penelitian yang dilakukan oleh Guzman et al. (2015) yang mengkaji mengenai stabilitas termodinamika dan migrasi ion tembaga pada silika amorf menggunakan DFT yang mengindikasikan puncak pertama RDF sistem Cu-Si pada 3,2 Å [12].

Pada setiap kurva RDF, radius yang sangat kecil menghasilkan RDF nol yang merupakan akibat dari kuatnya gaya tolak (repulsive force) pada nilai radius yang kecil. Kemudian muncul puncak paling tinggi pada sebuah radius yang tidak terlalu panjang, dimana hal ini menunjukkan bahwa probabilitas menemukan atom yang berpasangan pada radius tertentu ini lebih tinggi dibandingkan pada radius yang lebih panjang.

Pengaruh kecepatan awal atom terhadap RDF ditunjukkan oleh gambar 4a. Puncak kurva yang cukup lebar mengindikasikan keteraturan struktur yang rendah, dengan kata lain struktur amorf yang terbentuk cenderung cukup tinggi. Puncak pertama RDF simulasi 4,286 $\AA$ /ps dan $5 \AA /$ ps terjadi pada radius 3,05 $\AA$. Namun demikian, pada kecepatan $2 \AA /$ ps dan $10 \AA /$ ps terjadi pergeseran puncak pada radius $3,15 \AA$, yang menunjukkan kerapatan lokal atom cenderung lebih rendah.

Terkait dengan RDF, dapat dideskripsikan pula nilai bilangan koordinasi (gbr. 4b). Bilangan koordinasi secara umum menggambarkan banyaknya ikatan yang terbentuk antara atom referensi dengan atom-atom tetangga pada radius tertentu. Pada nilai kecepatan awal $2 \AA /$ ps dan 4,286 $\AA$ /ps cenderung tidak ada perbedaan pada bilangan koordinasi yang dihasilkan. Perbedaan terlihat pada nilai kecepatan awal $5 \AA /$ ps dan $10 \AA$ ps yang masing-masing menghasilkan bilangan koordinasi yang lebih rendah dan lebih tinggi dibandingkan dua nilai kecepatan awal lainnya. Hal ini berarti bahwa pada simulasi dengan kecepatan awal $10 \AA /$ ps kemungkinan akan didapatkan atom-atom tetangga lebih tinggi dibandingkan nilai-nilai kecepatan awal lainnya, dan pada simulasi dengan kecepatan awal $5 \AA$ ps berlaku sebaliknya. 


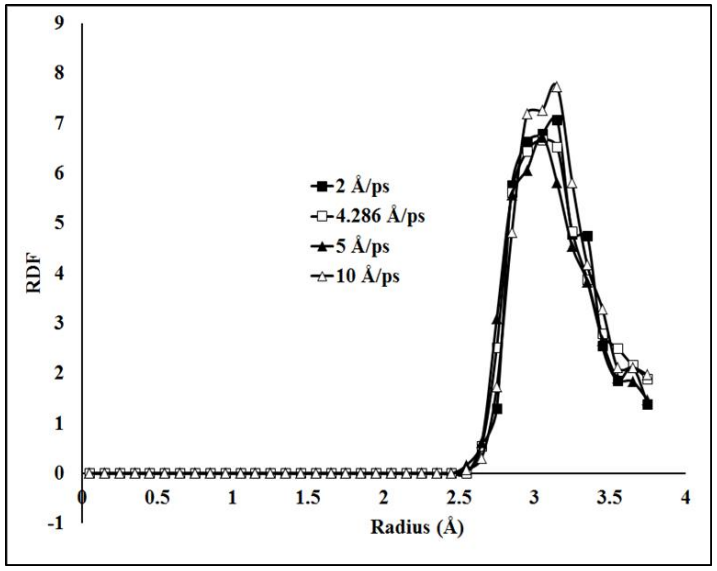

(a)

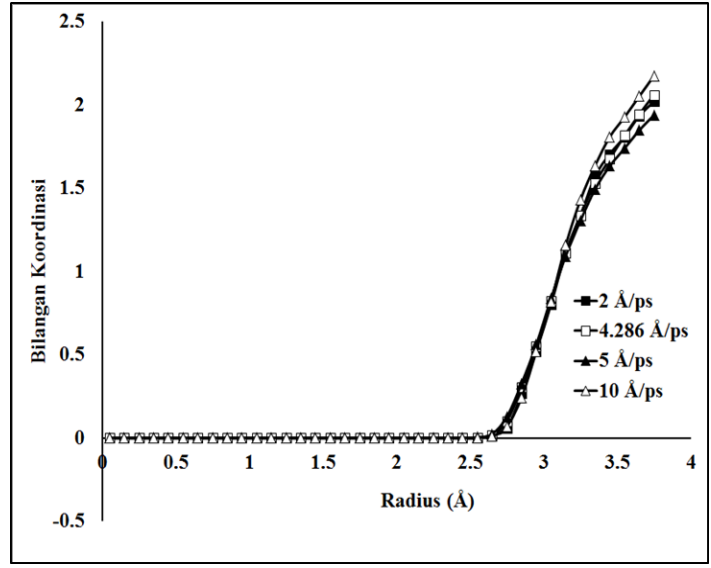

(b)

Gambar 4. Kurva variasi kecepatan awal atom tembaga (a) RDF dan (b) bilangan koordinasi

Pada variasi laju deposisi (gbr. 5a) nilai puncak pertama RDF pada 4,4 atom/ps, 57,6 atom/ps, dan 444,4 atom/ps berturut-turut adalah 8,$85 ; 6,67 ; 5,28$ yang terjadi pada kisaran radius 3,05-3,15 $\AA$ A. Pada sistem yang melibatkan dua jenis atom, dalam hal ini $\mathrm{Cu}$ dan $\mathrm{Si}$, RDF yang dihitung berupa $\mathrm{RDF}$ parsial yang memberikan informasi rapat probabilitas sebuah atom jenis pertama $(\mathrm{Cu})$ untuk memiliki tetangga berupa atom jenis kedua ( $\mathrm{Si}$ ) pada radius tertentu [13]. Ikatan antar sesamanya, yaitu $\mathrm{Cu}-\mathrm{Cu}$ dan $\mathrm{Si}-\mathrm{Si}$, tidak dimasukkan dalam perhitungan RDF ini. Pada durasi deposisi yang sama dan dengan laju deposisi yang rendah, $\mathrm{Cu}$ yang dideposisikan relatif lebih sedikit dibandingkan dengan laju deposisi yang tinggi. Hal ini berimplikasi bahwa probabilitas didapatkannya $\mathrm{Cu}$ yang berikatan dengan $\mathrm{Si}$ akan lebih besar, sehingga nilai RDF semakin tinggi. Sedangkan pada laju deposisi yang tinggi, atom $\mathrm{Cu}$ yang dideposisikan lebih banyak, menyebabkan tingginya ikatan $\mathrm{Cu}-$ $\mathrm{Cu}$ yang tidak dihitung sebagai RDF.

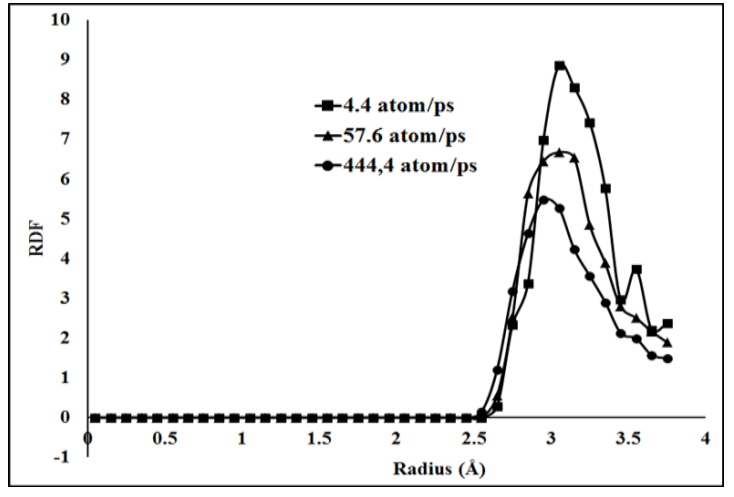

(a)

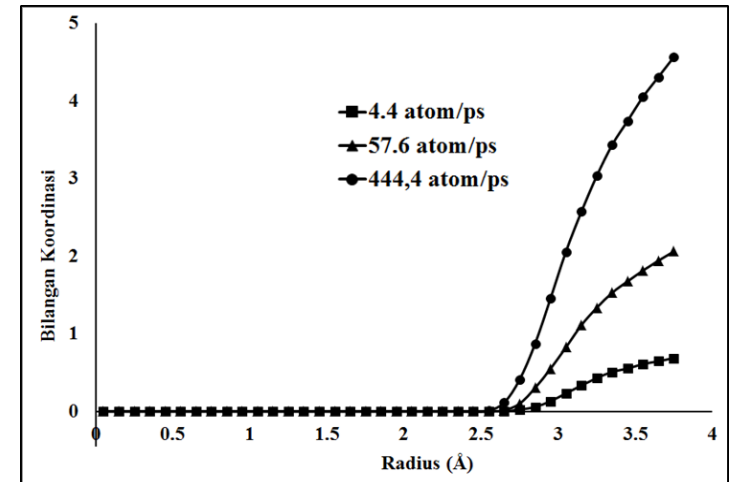

(b)

Gambar 5. Kurva variasi laju deposisi atom tembaga (a) RDF dan (b) bilangan koordinasi

Penjelasan tersebut juga terkait dengan nilai bilangan koordinasi yang dihasilkan (gbr. 5b). Pada durasi yang sama, atom yang dideposisikan dengan laju rendah akan lebih sedikit dibandingkan dengan laju tinggi. Hal ini berimplikasi jumlah $\mathrm{Si}$ yang dianggap berkoordinasi dengan $\mathrm{Cu}$ juga lebih sedikit. Sehingga menyebabkan rendahnya nilai bilangan koordinasi pada penggunaan laju deposisi yang rendah, dan sebaliknya. 


\section{Kesimpulan}

Berdasarkan simulasi dengan metode dinamika molekuler terlihat bahwa penggunaan laju deposisi yang rendah menghasilkan persentase amorf pada struktur akhir yang lebih rendah dibandingkan laju tinggi, sedangkan variasi kecepatan awal deposisi tidak menghasilkan perbedaan yang signifikan.

Pada semua variasi parameter puncak pertama kurva RDF terbentuk pada rentang radius 3,053,15 $\AA$, yang relatif konsisten dengan puncak pertama kurva RDF referensi pada radius 3,2 $\AA$. Dimana perbedaan nilai puncak pertama RDF yang terbentuk pada variasi kecepatan awal tidak begitu signifikan, sedangkan pada variasi laju deposisi nilai puncak pertama RDF semakin menurun seiring peningkatan laju deposisi. Berkaitan dengan ini, koordinasi atau ikatan antara atom-atom tembaga dengan atom-atom silikon semakin meningkat seiring peningkatan laju deposisi.

\section{Referensi}

[1] A. Priatmoko dan E. Harahap. (2017). "Implementasi Algoritma DES Menggunakan MATLAB". Jurnal Matematika UNISBA. Vol. 16 No.1 pp.11-19.

[2] M.E. Tuckerman dan G.J. Martyna. (2000). "Understanding Modern Molecular Dynamics: Techniques and Applications". J. Phys. Chem. B., Vol. 104 pp.159-178.

[3] L. Verlet. (1967). "Computer "Experiments" on Classical Fluids. I. Thermodynamical Properties of Lennard-Jones Molecules". Phys. Rev. Vol. 159 No. 1 pp.98-103.

[4] S.P. Kim, K.R. Lee, Y.C. Chung, M. Sahashi, dan Y.K. Kim. (2009). "Molecular dynamics simulation study of deposition and annealing behaviors of $\mathrm{Al}$ atoms on Cu surface". J. Appl. Phys., Vol. 105 pp.1-6.

[5] M. Joe, S. Kim, dan K. Lee. (2009). "Study on the Phase Transition Behavior of Ni Nano-Clusters Using Molecular Dynamics Simulation”. J. Comput. Theor. Nanosci., Vol. 6 No. 11 pp.2442-2445.

[6] R. Rasuli, K. Mostafavi, dan J. Davoodi. (2014). "Molecular dynamics simulation of graphene growth on $\mathrm{Ni}(100)$ facet by chemical vapor deposition". J. Appl. Phys., Vol. 115 pp.1-4.

[7] M. De Vivo, M. Masetti, G. Bottegoni, dan A. Cavalli. (2016). "Role of Molecular Dynamics and Related Methods in Drug Discovery". J. Med. Chem., Vol. 59 pp.4035-4061.

[8] J. Zhang, C. Liu, Y. Shu, dan J. Fan. (2012). "Growth and properties of Cu thin film deposited on Si(001) substrate: A molecular dynamics simulation study”. Applied Surface Science., Vol. 261 pp.690-696.

[9] B. Jelinek, S. Groh, M.F. Horstemeyer, J. Houze, S.G. Kim, G.J. Wagner, A. Moitra, dan M.I. Baskes. (2012). "MEAM Potentials for Al, Si, Mg, Cu, and Fe Alloys". Phys. Rev B., Vol. 85 pp.1-17.

[10] S. Hwang, Y. Li, Z. Hong. (2012). "Molecular dynamic simulation for $\mathrm{Cu}$ cluster deposition on $\mathrm{Si}$ substrate". Computational Materials Science., Vol. 56 pp.85-94.

[11] J. Tersoff. (1989). "Modeling solid-state chemistry: Interatomic potentials for multicomponent systems". Phys. Rev B., Vol. 39 No. 8 pp.5566-5568.

[12] D.M. Guzman, N. Onofrio, dan A. Strachan. (2015). "Stability and Migration of Small Copper Clusters in Amorphous Dielectrics". J. Appl. Phys., Vol. 117 pp.1-8.

[13] A.L. Thorneywork, R. Roth, D.G.A.L. Aarts, dan R.P.A. Dullens. (2014). "Communication: Radial distribution functions in a two-dimensional binary colloidal hard sphere system". J. Chem. Phys., Vol. 140 pp.1-5. 